Dermatologische Zeitschrift. 1920;30:I-IV

\title{
Contents, Vol. 30, 1920
}

Inhalts-Verzeichnis.

Originalarbeiten. seite

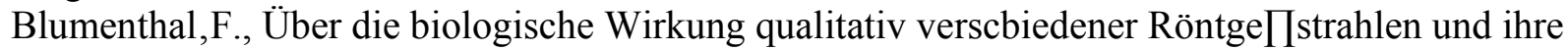
therapetitische

Verwendung bei Hautkrankheiter! 1

B«schke, A., Über die Anzeigepflicht bei Geschlechts-

kraBkbeiten 153

Eicke, F., Beiträge zur Gonorrhoeübertragung in der Ehe

(persönliche Immunität, nicht cohabitative Infektion) . 200 Habermann, R.., Über die

sogenannten Kńegsmelano $7 / 8$ en

und ihre Beziehungen zu den Teer- und Schmierölschädi-

gungen der Haut. (Hierzu Tafel I-V.)63

Keining, E., Über den serologischen Luesnachweis durch

Ausflockung nach der Methode von Sachs und Georgi. . 189 Klemm, G., Über die Therapie der Aktinomykose, nebst

Mitteilung eines geheilten Falles von Hautaktinomykose $217 \mathrm{~K} \mathrm{u} \mathrm{m} \mathrm{e} \mathrm{r} \mathrm{,} \mathrm{L.,} \mathrm{Ein} \mathrm{eigentümlicher}$ Fall von Lichen ruber planus

hypertrophicus 177

Zimmern, F., Über den Sitz des Primäraffekts, Positiv-

werden der Serumreaktion und daraxis zu ziehende thera-

peutische Forderungen 228

Gesellschaftsberichte.

Verhandlungen der Berliner Dermatologischen Gesellschaft

Sitzung vom 20. V. $1919 \quad 239$

„17. VI. 1919251

Gemeïnsch'aftliche Sitzung mit der Urologischen Gesellschaft

vom 15. VII. $1919 \quad .267$

Außerordentliche Sitzung aus Anlaß der Tagung der Lupus-

kommission vom 15. X. 1919279

$-\mathrm{IV}-$

Seite

Generalversammlung vom 11. XI. $1919 \quad 294$

Danische dermatologische Gesellschaft

119. Sitzung Dezember $1916 \quad 302$

„, Februar $1917 \quad 303$

„März 1917304

,April 1917305

„Mai 1917 ........ , ...... 306

„3. Oktober 1917 ....'......... 308 
„7. November $1917 \quad 309$

„5. Dezember 1917 . . 311

,6. Februar 1918 . 312

128. ๑, 6. März 1918 . . ... V . . . . . 314

129. „3. April $1918 \ldots \ldots \ldots \ldots ., 314$

Periodische Literatur. Zusammengestellt von Dr. Arthur

Alexander- Charlottenburg 316

Buchanzeigen 338

Sachregister 341

Namenregister 343 